\title{
Homeopathic drugs complementary, antidotal and inimical to Nux vomica produce stronger anti- alcoholic effect on toads than Nux vomica.
}

\author{
Atheni Konar ${ }^{1}$, Tandra Sarkar ${ }^{1}$, Indrani Chakraborty ${ }^{1,2}$, Nirmal Chandra Sukul ${ }^{1,3,4}$, \\ Anirban Sukul ${ }^{1,4}$, Rathin. Chakravarty ${ }^{1}$
}

(1) Molecular Homeopathy Research Unit, 30 Chowringhee Rd, Kolkata 16, India.

(2) Department of Zoology, Vidyasagar College for women, Kolkata, India.

(3) Department of Zoology, Visva-Bharati University, Santiniketan, India.

(4) Sukul Institute of Homeopathic Research, Shyambati, Santiniketan, India

Background: In homeopathy some drugs are known to act as complementary, antidotal or inimical to a particular drug. Practitioners can follow this rule when they apply one drug following another. Potentized Nux vomica can reduce acute hypnotic effect of alcohol on toads. Sulphur and Sepia are reported to be complementary to Nux-vom, while Coffea cruda and Zincum met are antidotal and inimical to Nux, respectively. The four drugs have been tested on the toad model to find out their actual therapeutic relationship with Nux vom. Objective: To verify the complementary effect of Sulphur and Sepia, antidotal effect of Coffea and inimical effect of Zincum in relation to Nux vom in the toad model. Methods: Five batches of toads, each comprising 20 individuals, were treated by partial immersion in a drug diluted with distilled water 1:500 for $20 \mathrm{~min}$. The control consisted of 90\% ethanol diluted with distilled water 1:500. The drugs were Nux vom $200 \mathrm{CH}$, Sulphur $200 \mathrm{CH}$, Sepia $200 \mathrm{CH}$, Coffea $200 \mathrm{CH}$ and Zincum $200 \mathrm{CH}$. Toads of each batch were separately exposed to $260 \mathrm{mM}$ ethanol solution and tested every $10 \mathrm{~min}$ to see if they had lost their righting reflex (RR). For this, each toad was laid on its dorsal surface. If it failed to turn on its ventrum in a cut-off time of $60 \mathrm{sec}$ it was considered to have lost it's RR. Four more batches of toads were pretreated with Nux vom $200 \mathrm{CH}$ and subsequently treated separately by Sulphur $200 \mathrm{CH}$, Sepia $200 \mathrm{CH}$, Coffea $200 \mathrm{CH}$ and Zincum $200 \mathrm{CH}$. All the toads were then exposed to $260 \mathrm{mM}$ ethanol solution to record their tolerance to ethanol anesthesia in terms of time to lose RR. Results: Toads treated with the five drugs took significantly longer time ( $\mathrm{P}<0.01$, one-way ANOVA) to lose RR than those treated with the control. The time taken to lose RR was significantly longer (P<0.01, one-way ANOVA) with Sulphur $200 \mathrm{CH}$, Sepia $200 \mathrm{CH}$, Coffea $200 \mathrm{CH}$ and Zincum $200 \mathrm{CH}$ than with Nux vom $200 \mathrm{CH}$ alone. The situation was same when Nux treatment was followed by each of the four drugs. Of the five drugs Coffea showed the strongest anti-hypnotic effect. Conclusion: 1. Drugs complementary, antidotal and inimical to Nux vom showed the same anti-alcoholic effect as Nux in terms of increased tolerance to alcohol anesthesia. 2. The anti-alcoholic effect of Nux vom was markedly superseded by the above four drugs. 3. Of all the drugs tested Coffea showed the strongest antialcoholic effect. 4. It appears that the above four drugs produced their individual dominant effect cancelling the individual effect of Nux vom.

Keywords: anti-alcoholic effect, antidotal, inimical. 


\section{(c) BY-NC-ND Licensed to GIRI}

Support: authors declare that this study received no funding

Conflict of interest: authors declare there is no conflict of interest

Received: March 28 ${ }^{\text {th }}$ 2014; Revised: May 10th 2014; Published: June 30 2014.

Correspondence author: Nirmal Chandra Sukul, ncsukul@gmail.com, www.sukulhomeopathy.com.

How to cite this article: Konar A, Sarkar T, Chakraborty I, Sukul NC, Sukul A, Chakravarty R. Homeopathic drugs complementary, antidotal and inimical to Nux vomica produce stronger anti-alcoholic effect on toads than Nux. Int J High Dilution Res [online]. 2014 [cited YYYY Month dd]; 13(47):119-120. Proceedings of the XXVIII GIRI Symposium; 2014 Jun 20-22; Sighisoara $\quad$ (Romania). $\quad$ GIRI; 2014; from: http://www.feg.unesp.br/ ojs/index.php/ijhdr/article/view/732/708 